\title{
Sistem Kendali Gimbal 2-Sumbu Sebagai Tempat Kamera Pada Quadrotor Menggunakan PID Fuzzy
}

\author{
M. Saiful Haris*1 ${ }^{* 1}$ Andi Dharmawan ${ }^{2}$, Catur Atmaji ${ }^{3}$ \\ ${ }^{1}$ Program Studi S1 Elektronika dan Instrumentasi, FMIPA UGM, Yogyakarta, Indonesia \\ ${ }^{2,3}$ Departemen Ilmu Komputer dan Elektronika, FMIPA UGM, Yogyakarta, Indonesia

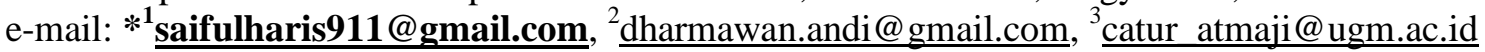

\section{Abstrak}

Sistem kendali pada camera gimbal pada penelitian ini berfungsi untuk mengatasi perubahan sudut kemiringan yang terjadi akibat manuver pada quadrotor. Sistem kendali PID dengan metode classical tuning memiliki kelemahan, salah satunya nilai konstanta PID yang tidak dapat secara mandiri menyesuaikan dengan lingkungannya, sehingga diusulkan menggunakan kendali PID fuzzy.

Camera gimbal yang digunakan pada penelitian ini memiliki rancangan mekanik dengan dua buah joint (pitch dan roll) dan motor BLDC sebagai aktuatornya. Perubahan sudut yang terjadi pada sumbu pitch dan roll menjadi umpan balik sistem. Kemudian, logika fuzzy akan menala konstanta PID berdasarkan umpan balik tersebut.

Hasil pengujian sistem pada camera gimbal 2-sumbu menunjukkan kendali PID fuzzy menghasilkan respon yang lebih baik dalam parameter risetime, overshoot, dan settlingtime dibandingkan dengan kendali PID. Rentang nilai masukan error sebesar $\left[-30^{\circ} 30^{\circ}\right]$ dan delta error sebesar $\left[-10^{\circ} 10^{\circ}\right]$ pada sumbu pitch dan roll. Rentang nilai keluaran untuk sumbu pitch yaitu, Kp sebesar [40,2 46,2], Ki sebesar [10,7 20,7], dan Kd sebesar [0,05 0,15]. Rentang nilai keluaran untuk sumbu roll yaitu, Kp sebesar [6,4 16,4], Ki sebesar [17,3 27,3], dan Kd sebesar $[0,08$ 0,16]. Diperoleh kecepatan respon pada sumbu pitch sebesar 0,12 detik dan pada sumbu roll sebesar 1,07 detik.

Kata kunci-BLDC, pitch, roll

\section{Abstract}

The function of camera gimbal control system that use in this research is to serves with the angle changes that occur due quadrotor maneuver. The PID control with tuning classical method has weakness, which is the PID variable not independently adjust to the environment, thus proposed using PID fuzzy control.

Gimbal camera used in this study has a mechanical design with two joint (pitch and roll) and the BLDC motor as actuator. The angle changes that occur in the pitch and roll axis will be a feedback system. Then, fuzzy logic will tune the PID variable based on that feedback.

Results of testing the system on 2-axis gimbal camera shows the PID fuzzy control generates better response in parameter risetime, overshoot, and settlingtime compared with PID control. Error input value range of $\left[-30^{\circ} 30^{\circ}\right]$ and delta error of $\left[-10^{\circ} 10^{\circ}\right]$ on the pitch and roll axes. The range of the output value for the pitch axis is, Kp at [40.2 46.2], Ki at [10.7 20.7], and Kd of [0.05 to 0.15]. The range of the output value for the roll axis is, Kp at [6.4 16.4], Ki at [17.3 to 27.3], and Kd at [0.08 0.16]. Speed response speed of pitch axis is 0.12 second and the roll axis is 1.07 seconds.

Keywords-BLDC, pitch, roll 


\section{PENDAHULUAN}

Camera gimbal adalah alat penstabil kamera, yang berfungsi untuk menghasilkan gambar atau video tanpa terpengaruh oleh kemiringan atau guncangan yang terjadi ketika pengambilan gambar atau video berlangsung. Memanfaatkan kerja gimbal yang dapat bergerak bebas pada porosnya mengakibatkan camera gimbal dapat menyesuaikan orientasi pergerakan ketika terjadi perubahan, sehingga kamera yang ditempatkan pada camera gimbal akan tetap stabil pada tempatnya.

Pada perkembangannya, camera gimbal dapat diaplikasikan pada quadrotor. Quadrotor merupakan pesawat tanpa awak (Unmanned Aerial Vehicle) yang memiliki 4 baling-baling dengan 4 buah rotor sebagai alat penggeraknya. Camera gimbal pada quadrotor digunakan untuk berbagai macam aplikasi di bidang fotografi udara yaitu, pelacakan target, pemetaan, navigasi otonomus dan lainnya [1].

Pada saat quadrotor malakukan manuver, maka keseluruhan dari body quadrotor akan berubah kemiringannya termasuk dengan camera gimbal yang ditempatkan pada quadrotor. Perubahan kemiringan yang terjadi pada quadrotor akan menyebabkan camera gimbal tidak dapat mempertahankan orientasinya, sehingga akan sangat mempengaruhi proses pengambilan gambar atau video. Oleh karena itu, ketika camera gimbal dipasangkan pada quarotor diperlukanlah sebuah sistem kendali untuk camera gimbal. Sistem kendali yang diharapkan adalah sistem kendali yang mampu mengatasi perubahan kemiringan yang terjadi dari quadrotor.

Salah satu metode kendali yang umum digunakan adalah Kendali PID. Kendali PID memiliki 3 buah gain yang bekerja berdasarkan error sistem, yaitu Konstanta proporsional (Kp), konstanta integratif (Ki), dan konstanta derivatif (Kd) [2]. Sebuah sistem dapat memiliki respon yang stabil jika dilakukan penalaan dengan menghasilkan konstanta $\mathrm{Kp}$, Ki, dan Kd yang tepat. Salah satu metode umum yang digunakan untuk penalaan $\mathrm{Kp}, \mathrm{Ki}$, dan $\mathrm{Kd}$ adalah classical tunning [3].

Metode penalaan classical tunning memiliki kelemahan, salah satunya nilai konstanta $\mathrm{Kp}, \mathrm{Ki}$, dan $\mathrm{Kd}$ tidak dapat secara mandiri menyesuaikan dengan lingkungannya [4]. Apabila sistem kendali PID dibuat sangat sensitif, maka respon sistem terhadapat gangguan menghasilkan overshoot besar yang mengakibatkan terjadinya osilasi yang semakin besar. Bila dibuat kurang sensitif, maka akan menghasilkan overshoot kecil, tetapi akan memperbesar risetime. Oleh karena itu, dibutuhkan suatu kendali yang dapat secara mandiri menala konstanta PID yang menyesuaikan dengan lingkungannya. Salah satu kendali yang dapat menangani masalah tersebut adalah dengan kendali PID fuzzy.

Sistem kendali PID Fuzzy (A Fuzzy PID Controller) menggunakan kontroler PID klasik sebagai pondasi dimana digunakan penalaran fuzzy dan variabel ruang input untuk meregulasi gain dari PID [5].

\section{METODE PENELITIAN}

\subsection{Analisis Sistem}

Gimbal memiliki joint untuk menunjang pergerakan pada sebuah sumbu. Pada setiap joint terdapat motor sebagai aktuatornya. Konfigurasi gimbal dapat bervariasi berdasarkan jumlah sumbu geraknya. Agar dapat mempertahankan orientasi, tiap motor yang terdapat pada joint harus dikendalikan antara sudut yang terjadi dengan gerakan motornya, sehingga dibutuhkan kendali untuk mempertahankan orientasi. Ada beberapa parameter yang 
mempengaruhi dalam memepertakan orientasi gimbal yaitu, gerak motor dan koordinat body frame yang ditempatkan kamera atau end effector.

Motor yang digunakan sebagai aktuator pada gimbal 2-sumbu penelitian ini adalah jenis motor brushless DC. Motor brushless DC memiliki 3 buah masukan dengan konfigurasi kumparan stator delta. Tiap masukan pada motor brushless DC mengatur nilai PWM berbentuk sinusoidal dengan beda fase tiap masukan sebesar $120^{\circ}$ yang akan mempengaruhi medan magnet pada stator, sehingga rotor akan bergerak mengikuti perubahan medan magnet yang terjadi pada stator. Jika nilai perubahan PWM yang menyerupai bentuk sinusoidal berlawanan arah jarum jam (counter clockwise) maka motor brushless DC juga akan bergerak counter clockwise. Sebaliknya, jika perubahan sinusoidal PWM searah jarum jam (clockwise) maka motor brushless DC juga akan bergerak clockwise. Perubahan sudut motor dengan nilai perubahan nilai PWM tidak liniear, sehingga perlu adanya sebuah sensor sudut sebagai umpan balik untuk dapat bergerak mendekati atau sampai kepada sudut yang diinginkan.

Penempatan kamera pada gimbal biasanya ditempatkan pada end efector atau body frame paling akhir, dalam sistem ini ditempatkan pada body frame (2). Karena dalam sistem ini yang ingin dikendalikan adalah orientasi kamera, maka harus ada hubungan antara koordinat kamera dengan sudut gimbal yang dihasilkan. maka sensor IMU perlu diletakkan pada body frame (2) untuk mengetahui kondisi orientasi kamera. Pada sistem ini jenis gimbal yang digunakan adalah gimbal 2-sumbu, yang memiliki pergerakan pada rotasi roll dan pitch. Sensor IMU digunakan untuk membaca nilai dari sudut orientasi roll dan pitch. Pembacaan sensor IMU dalam sistem ini menggunakan metode fussion DMP. Perhitungan dari accelerometer dan gyroscope akan menghasilkan nilai sudut orientasi roll dan pitch dengan menggunakan library MPU6050.

Rentang nilai yang dapat terjadi pada pergerakan sumbu pitch dan roll adalah sebesar $30^{\circ}$ clockwise dan counter clockwise, karena gimbal akan dipasangkan pada quadrotor yang memiliki batas kemiringan sudut sebesar $30^{\circ}$ clockwise dan counter clockwise. Nilai tersebut yang kemudian akan menjadi rentang nilai himpunan masukan fuzzy pada sistem kendali gimbal 2-sumbu.

Terdapat beberapa parameter acuan yang dapat dijadikan acuan untuk menentukan tingkat keberhasilan dari penelitian ini. Parameter keberhasilan dari sistem kendali gimbal 2sumbu ini dapat diketahui dari beberapa kondisi yang disebutkan sebagai berikut:

1. Nilai steady state error dibawah batas toleransi 5\% dari nilai maksimal [2], yaitu sebesar $30^{\circ}$ clockwise dan counter clockwise untuk sudut roll dan pitch yang dikendalikan, sehingga batas tolerasni sudut adalah $1,5^{\circ}$ clockwise dan counter clockwise untuk sudut pitch dan roll.

2. Risetime yang dihasilkan untuk sudut pitch lebih cepat atau sama dengan 1 detik dan roll lebih cepat atau sama dengan 2 detik [6].

3. Settling time yang dihasilkan untuk sudut pitch lebih cepat dari 2 detik dan roll lebih cepat dari 3 detik [6].

4. Maximum overshoot untuk sudut pitch dan roll yang dihasilkan diantara $5^{\circ}$ clockwise dan counter clockwise untuk sudut pitch dan $10^{\circ}$ clockwise dan counter clockwise untuk sudut roll [7].

\subsection{Arsitektur Sistem}

Rancangan arsitektur sistem yang digunakan pada penelitian ini secara keseluruhan digambarkan pada Gambar 1. Komponen sensor yang digunakan adalah sensor inertial measurement unit (IMU) GY-521. Sensor IMU GY-521 merupakan modul yang berisikan accelerometer dan gyroscope. Pembacaan Sensor IMU yang digunakan pada sistem ini menggunakan metode sensor fusion DMP. Metode sensor fusion DMP adalah dengan cara menggabungkan pembacaan dari accelerometer dan gyroscope pada Sensor IMU untuk 
menghasilkan nilai orientasi roll dan pitch dengan menggunakan library MPU6050. Hasil pembacaan dari Sensor IMU kemudian akan diolah mikrokontroller untuk menentukan posisi dari kamera yang ditempatkan pada gimbal, sehingga dapat dilakukan kendali pada gimbal agar dapat mengatasi perubahan orientasi yang terjadi.

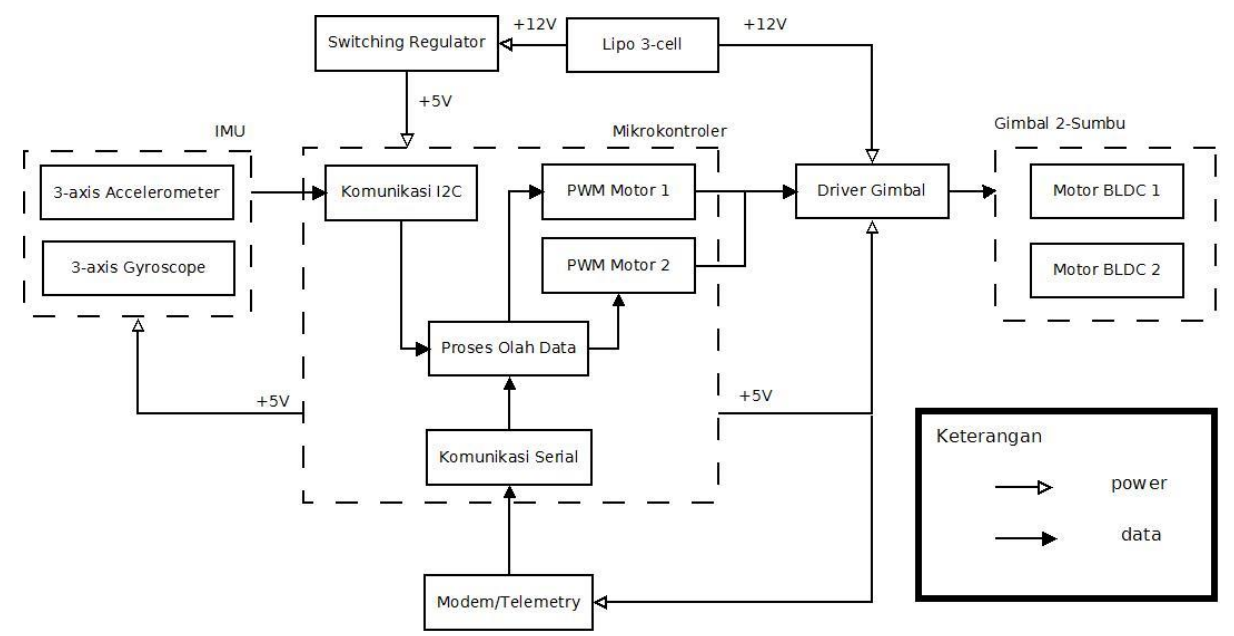

Gambar 1 Arsitektur sistem gimbal 2-sumbu

\subsection{Pemodelan Gimbal 2-Sumbu}

Pemodelan gimbal 2-sumbu dibagi menjadi beberapa bagian yaitu, pemodelan matematika dari kinematika gimbal, pemodelan motor sebagai aktuator gimbal, dan juga kendali PID. Pemodelan gimbal yang dibuat pada penelitian ini berfungsi untuk melalukan pendekatan sistem secara simulasi.

\subsubsection{Kinematika gimbal 2-sumbu}

Gimbal 2-sumbu terdiri dari dua buah joints yang dapat berputar pada sudut $\theta_{1}$ dan $\theta_{2}$ sepanjang sumbu pitch dan sumbu roll. Gimbal 2-sumbu yang digunakan terdiri dari tiga body frame (body (0), body (1), dan body (2)). Pada Gambar 2 ditunjukkan hubungan antar body frame. Body (0), body (1), dan body (2) dalam bentuk $\mathrm{X}_{0} \mathrm{Y}_{0} \mathrm{Z}_{0}, \mathrm{X}_{1} \mathrm{Y}_{1} \mathrm{Z}_{1}$, dan $\mathrm{X}_{2} \mathrm{Y}_{2} \mathrm{Z}_{2}$.
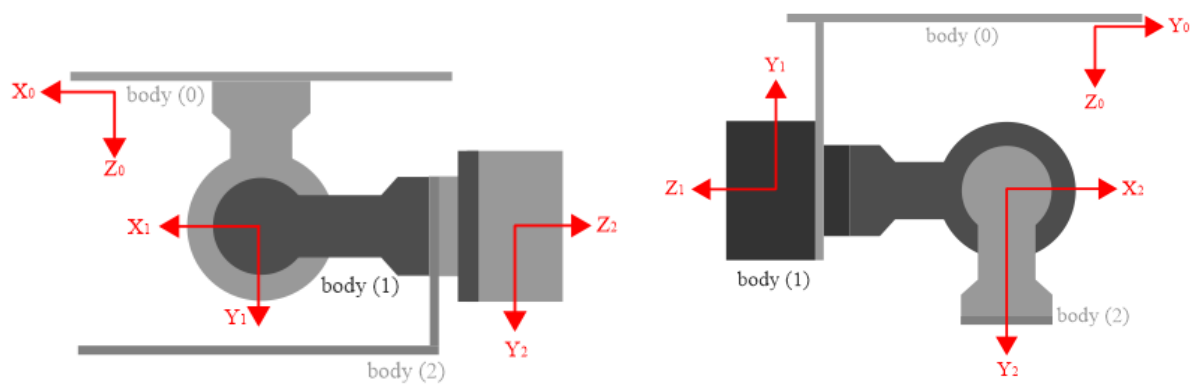

Gambar 2 Konfigurasi gimbal 2-sumbu (kiri) tampak depan, (kanan) tampak samping

Untuk mengetahui pergerakan dari end effector atau dalam Gambar 2 ditunjukkan dengan body frame (2) dapat dilakukan dengan pendekatan forward kinematik menggukan kaidah Denavit-Hartenberg [8]. Rotation matrix antara body frame (0) dengan body frame (1) ditunjukkan pada persamaan (1).

$$
{ }^{0} R_{1}=\left[\begin{array}{ccc}
1 & 0 & 0 \\
0 & \cos \theta_{1} & -\sin \theta_{1} \\
0 & \sin \theta_{1} & \cos \theta_{1}
\end{array}\right]
$$


Sedangkan rotation matrix untuk body frame (1) dengan body frame (2) ditunjukkan pada persamaan (2).

$$
{ }^{1} R_{2}=\left[\begin{array}{ccc}
\cos \theta_{2} & 0 & \sin \theta_{2} \\
0 & 1 & 0 \\
-\sin \theta_{2} & 0 & \cos \theta_{2}
\end{array}\right]
$$

Sehingga didapatkan total rotation matrix untuk body frame (0), body frame (1), dan body frame (2) pada persamaan (3).

$$
{ }^{0} R_{2}=\left[\begin{array}{ccc}
\cos \theta_{2} & 0 & \sin \theta_{2} \\
\sin \theta_{1} \sin \theta_{2} & \cos \theta_{1} & -\sin \theta_{1} \sin \theta_{2} \\
-\cos \theta_{1} \sin \theta_{2} & \sin \theta_{1} & \cos \theta_{1} \cos \theta_{2}
\end{array}\right]
$$

Kemudian untuk menentukan sudut end effector atau body frame (2) yang diinginkan ditempatkan Sensor IMU. Sensor IMU berfungsi untuk memberikan nilai sudut pada end effector. Sehingga dapat diketahui nilai error antar sudut yang diinginkan dengan sudut asli dari hasil Sensor IMU. Hubungan tersebut ditunjukkan pada persamaan (4) dan (5).

$$
\begin{aligned}
& \varepsilon_{1}=\alpha_{1 \text { setpoint }}-\alpha_{1} \\
& \varepsilon_{2}=\alpha_{2 \text { setpoint }}-\alpha_{2}
\end{aligned}
$$

Dari persamaan (4) dan (5) dapat dibuat persamaan untuk rotation matrix dari error yang terjadi pada body frame (2) seperti yang ditunjukkan pada persamaan (6),

$$
{ }^{2} R_{e}=\left[\begin{array}{ccc}
\cos \varepsilon_{2} & 0 & \sin \varepsilon_{2} \\
\sin \varepsilon_{1} \sin \varepsilon_{2} & \cos \varepsilon_{1} & -\sin \varepsilon_{1} \sin \varepsilon_{2} \\
-\cos \varepsilon_{1} \sin \varepsilon_{2} & \sin \varepsilon_{1} & \cos \varepsilon_{1} \cos \varepsilon_{2}
\end{array}\right]
$$

Dengan menggunakan inverse kinematik, didapatkan hubungan antara total rotation matrix dengan error yang terjadi pada body frame (2) seperti yang ditunjukkan pada persamaan (7),

$$
{ }^{0} R_{\varepsilon}(\theta, \alpha)={ }^{0} R_{2}(\theta){ }^{2} R_{\varepsilon}(\alpha)
$$
persamaan (8).

$\theta_{1}$, dan $\theta_{2}$ adalah sudut motor saat ini. untuk sudut motor yang baru dapat dilihat pada

$$
{ }^{0} R_{\varepsilon}\left(\theta_{\text {baru }}\right)={ }^{0} R_{\varepsilon}(\theta, \varepsilon)
$$

Dari persamaan (8) dapat dilihat bahwa body frame (2) adalah sama dengan frame error $(\varepsilon)$, Sehingga akan didapatakan persamaan seperti yang ditunjukkan pada persamaan (9),

$$
{ }^{0} R_{\varepsilon}\left(\theta_{\text {baru }}\right)={ }^{0} R_{2}(\theta){ }^{2} R_{\varepsilon}(\alpha)
$$

Dari persamaan (9) dapat dibuat hubungan antara error terhadap body frame 0, permisalan hasil perkalian matriks yang terjadi seperti yang ditunjukkan pada persamaan (10).

$$
{ }^{0} R_{2}(\theta){ }^{2} R_{\varepsilon}(\alpha)=\left[\begin{array}{lll}
r_{11} & r_{12} & r_{13} \\
r_{21} & r_{22} & r_{23} \\
r_{31} & r_{32} & r_{33}
\end{array}\right]
$$


Pada persamaan (10) $\mathrm{r}_{\mathrm{ij}}$ merupakan representasi dari komponen didalam matriks ${ }^{0} R_{3}(\theta){ }^{3} R_{\varepsilon}(\alpha)$. Dengan menggunakan inverse kinematik dapat diketahui bahwa nilai dari sudut motor yang baru, sehingga akan dihasilkan persamaan (11) dan persamaan (12).

$$
\begin{gathered}
\theta_{1 \text { baru }}=\tan ^{-1}\left(-\frac{r_{23}}{r_{33}}\right) \\
\theta_{2 \text { baru }}=\sin ^{-1}\left(r_{13}\right)
\end{gathered}
$$

$\theta_{1 \text { baru }}$ dan $\theta_{2 \text { baru }}$ adalah sudut motor baru yang diinginkan agar kamera pada gimbal dapat mempertahankan orientasi.

\subsubsection{Pemodelan Motor}

Kita dapat memperoleh model matematik dari motor DC dengan mengaplikasikan hukum Kirchhoff kedalam kumparan armature dan hukum II Newton kedalam mekanik motor [9]. Sehingga, didapatkan persamaan (13) untuk penerapan Hukum Kirchoff dan persamaan (14) untuk penerapan hukum II Newton.

$$
\begin{gathered}
L \frac{d i}{d t}+R i=V-K \dot{\theta} \\
J \ddot{\theta}+b \dot{\theta}=K i
\end{gathered}
$$

Kemudian, dari persamaan (13) dan (14) dirubah kedalam bentuk Laplace menjadi

$$
\begin{gathered}
(L s+R) I(s)=V(s)-K s \theta(s) \\
s(J s+b) \theta(s)=K I(s)
\end{gathered}
$$

Dari persamaan (15) dan (16) kita dapat mensubtitusikan menjadi persamaan yang ditunjukkan pada persamaan (17).

$$
\frac{\theta(s)}{V(s)}=\frac{K}{s\left[(L s+R)(J s+B)+K^{2}\right]}
$$

Dimana, $K$ adalah back emf (Nm/A), $L$ adalah induktansi $(\mathrm{H}), R$ adalah resistansi $(\Omega), J$ adalah momen inersia dari motor $\left(\mathrm{Kg} \mathrm{m}^{2} / \mathrm{s}^{2}\right)$, dan $B$ adalah rasio damping $(\mathrm{Nm} / \mathrm{rad})$.

Karena dalam penelitian ini menggunakan 2 buah motor, yaitu motor yang dipasang pada sumbu roll dan sumbu pitch. maka untuk persamaan (17) berlaku untuk motor pada sumbu roll maupun sumbu pitch. Namun, nilai $J$ atau inersia berbeda antara motor pada sumbu roll dan sumbu pitch, karena dipengaruhi beban yang berbeda antara motor pada sumbu roll dan sumbu pitch. Nilai inersia pada motor sumbu roll dan motor sumbu pitch ditunjukkan pada persamaan (18) untuk sumbu roll dan (19) untuk sumbu pitch.

$$
\begin{aligned}
& I_{x x}=\sum_{j=1}^{n}\left(I_{G_{x x_{j}}}+m_{j}\left(y_{j}^{2}+z_{j}^{2}\right)\right) \\
& I_{y y}=\sum_{j=1}^{n}\left(I_{G_{y y_{j}}}+m_{j}\left(x_{j}^{2}+z_{j}^{2}\right)\right)
\end{aligned}
$$

Dimana $\mathrm{I}_{\mathrm{G}_{\mathrm{xx}_{\mathrm{j}}}}$ dan $\mathrm{I}_{\mathrm{G}_{\mathrm{yy}}}$ adalah inersia pada sumbu $\mathrm{x}$ atau pitch dan $\mathrm{y}$ atau roll, serta $\mathrm{j}$ menunjukan komponen ke-j yang mempengaruhi inersia; $\mathrm{x}_{\mathrm{j}}$ dan $\mathrm{y}_{\mathrm{j}}$ adalah jarak center of gravity masing masing komponen ke-j ke poros putar motor pada sumbu $\mathrm{x}$ dan $\mathrm{y}$; dan $\mathrm{m}_{\mathrm{j}}$ adalah massa dari masing-masing komponen ke-j [10]. 


\subsection{Rancangan Sistem Kendali}

Salah satu sistem kendali yang dapat digunakan untuk mempertahankan orientasi kamera pada gimbal adalah sistem kendali PID (Proportional Integral Derivative). Persamaan PID ditunjukkan pada persamaan (20). Dimana $K p$ adalah konstanta proportional, $K i$ adalah konstanta integral, dan $K d$ adalah konstanta derivative, dengan keluaran $u$, dan $e$ merupakan masukan error yang berasal nilai masukan referensi $r$ dikurangi dengan nilai masukan sudut $y$. Serta dimana $t$ adalah waktu saat ini.

$$
u(t)=K p \cdot e(t)+K i \int_{0}^{t} e(t) d t+K d \frac{d e}{d t}
$$

Logika fuzzy dapat digunakan untuk mengoptimalkan respon dari sistem kendali PID dengan menala konstanta $\mathrm{Kp}, \mathrm{Ki}$, dan $\mathrm{Kd}$ berdasarkan masukan error dan delta error [11]. Lima nilai linguistik digunakan dalam rancangan himpunan masukan fuzzy yang menggambarkan error dan delta error ditunjukkan pada Gambar 3. Untuk himpunan fuzzy error, nilai-nilai tersebut adalah NB (Negatif Besar), N (Negatif), O (Nol), P (Positif), dan PB (Positif Besar). Untuk himpunan fuzzy delta error, nilai-nilai tersebut adalah DNB (Delta Negatif Besar), DN (Delta Negatif), DO (Delta Nol), DP (Delta Positif),dan DPB (Delta Positif Besar).
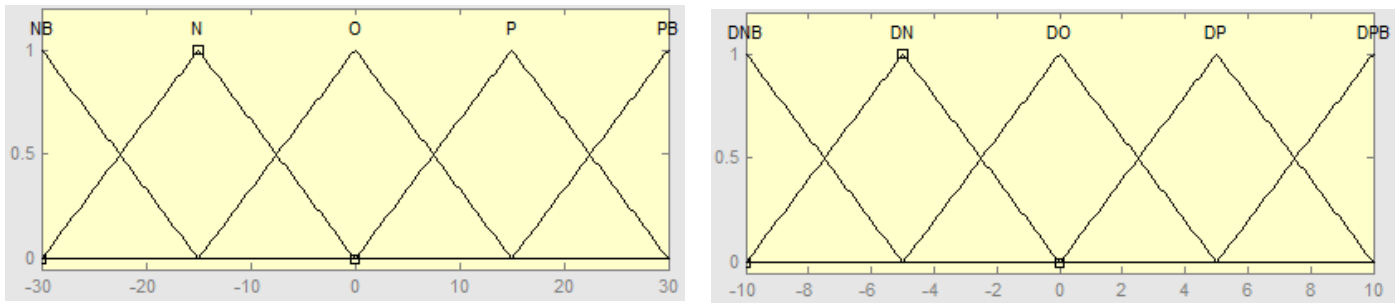

Gambar 3 Himpunan masukan fuzzy (kiri) error, (kanan) delta error

Tabel 1 merupakan rancangan aturan fuzzy yang akan diimplementasikan pada tahap inference. Terdapat sebanyak 25 aturan fuzzy (rule base) yang ditanamkan pada tahap inference. FIS yang digunakan pada kendali ini adalah metode Mamdani. Alasan pemilihan FIS dengan metode Mamdani yaitu karena keluaran FIS tipe Mamdani berupa fuzzy set dan bukan sekadar inversi dari fungsi keanggotaan keluaran. Keluaran pada FIS yang diinginkan yaitu berupa nilai pada fuzzy set untuk memetakan nilai konstanta PID berdasarkan error dan delta error.

Tabel 1 Aturan fuzzy untuk Kp, Ki, dan Kd [12]

\begin{tabular}{|c|c|c|c|c|c|c|}
\hline \multirow{2}{*}{ Kp dan Ki } & \multicolumn{5}{|c|}{ Error } \\
\cline { 2 - 7 } & NB & N & O & P & PB \\
\hline \multirow{3}{*}{} & DNB & SB & B & T & B & SB \\
\cline { 2 - 7 } & DN & B & T & K & T & B \\
\cline { 2 - 7 } & DO & T & K & SK & K & T \\
\cline { 2 - 7 } & DP & B & T & K & T & B \\
\cline { 2 - 7 } & DPB & SB & B & T & B & SB \\
\hline \multirow{2}{*}{} & & & & &
\end{tabular}

\begin{tabular}{|c|c|c|c|c|c|c|}
\hline \multirow{2}{*}{\multicolumn{2}{|c|}{ Kd }} & \multicolumn{5}{|c|}{ Error } \\
\hline & & $\overline{\mathrm{NB}}$ & $\overline{\mathbf{N}}$ & $\bar{O}$ & $\bar{P}$ & PB \\
\hline \multirow{5}{*}{ 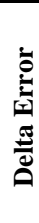 } & DNB & SK & K & $\mathrm{T}$ & K & SK \\
\hline & DN & K & $\mathrm{T}$ & B & $\mathrm{T}$ & K \\
\hline & DO & $\mathrm{T}$ & B & SB & B & $\mathrm{T}$ \\
\hline & DP & $\mathrm{K}$ & $\mathrm{T}$ & B & $\mathrm{T}$ & $\mathrm{K}$ \\
\hline & DPB & SK & $\mathrm{K}$ & $\mathrm{T}$ & K & SK \\
\hline
\end{tabular}

Lima nilai linguistik digunakan dalam rancangan himpunan keluaran fuzzy yang menggambarkan nilai Kp, Ki dan Kd. Pada himpunan keluaran fuzzy ditunjukkan pada Gambar 4. Nilai-nilai tersebut adalah SK (Sangat Kecil), K (Kecil), T (Tengah), B (Besar), dan SB (Sangat Besar). kemudian untuk inisial huruf awal dari nilai linguistik yaitu P, I dan D merupakan inisial dari konstanta PID, sedangkan huruf akhirnya itu P merupakan inisial untuk sumbu picth. Nilai B dan A pada rentang himpunan akan dicari melalui eksperimen. Sedangkan 
nilai O pada rentang himpunan merupakan nilai yang didapat melalui penalaan Ziegler-Nichols.

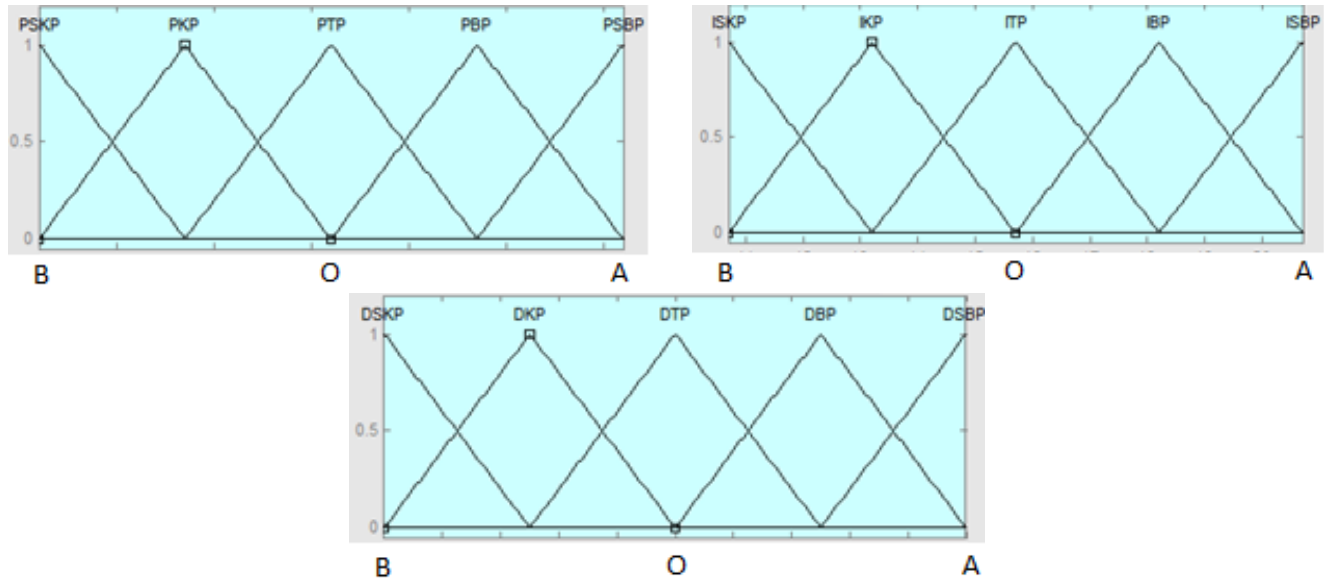

Gambar 4 Himpunan masukan fuzzy (kiri) Kp, (kanan) Ki, dan (bawah) Kd

Secara keseluruhan sistem kendali yang akan digunakan pada penelitian ini ditunjukkan pada Gambar 5. Pada Gambar 5,e0 dan juga e $\phi$ menunjukkan error yang terjadi pada sumbu pitch dan roll. Kemudian sistem kendali fuzzy memiliki masukan berupa error dan juga delta error yang diwakili oleh e $\theta$ dan juga e $\theta(n)$ - e $\theta(n-1)$ pada sumbu pitch dan e $\theta$ dan juga e $\phi(n)$ e $\phi$ (n-1) pada sumbu roll, sedangkan keluarannya berupa konstanta $\mathrm{Kp}, \mathrm{Ki}$, dan $\mathrm{Kd}$ yang akan digunakan oleh kendali PID.

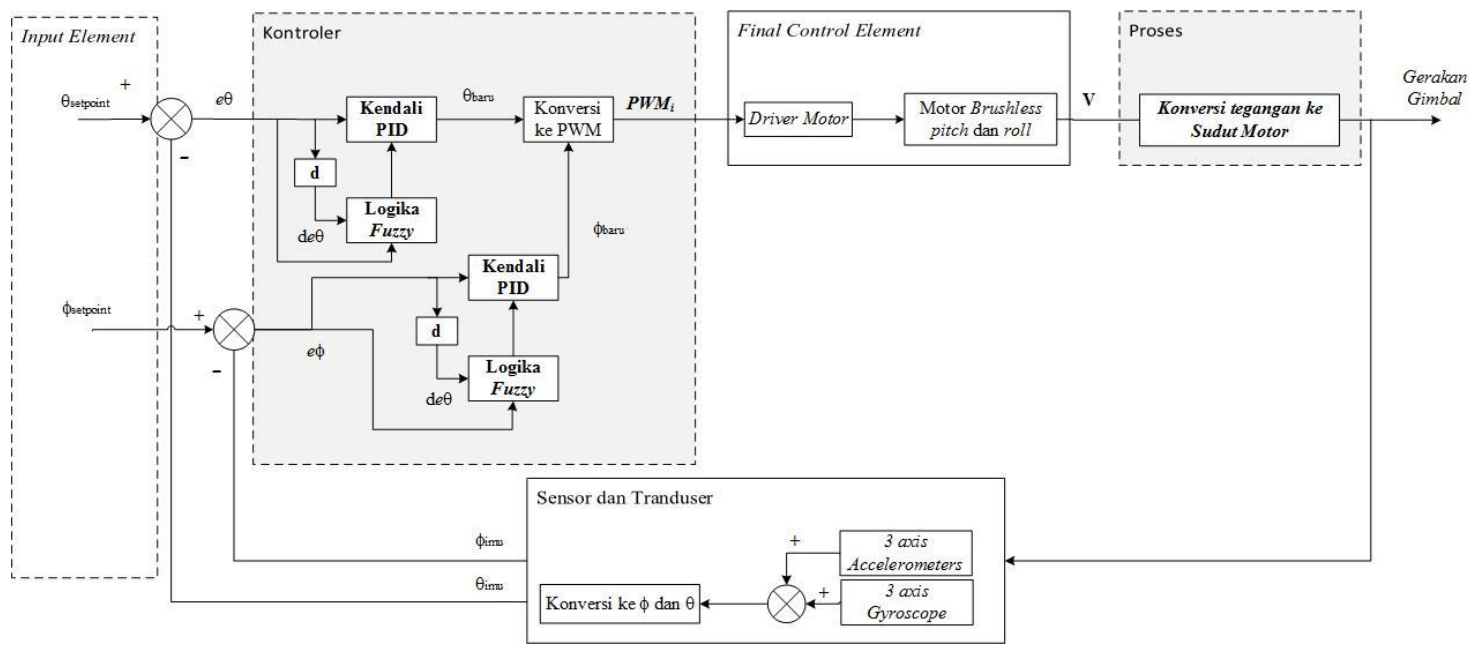

Gambar 5 Diagram blok kendali sistem

\section{HASIL DAN PEMBAHASAN}

Simulasi pemodelan ditujukan untuk melihat bagaimana respon sistem gimbal 2-sumbu bekerja ketika diterapkan kendali PID Ziegler-Nichols. Dimulai dengan kinematika, pemodelan motor brushless DC pada gimbal, hingga kendali PID diimplementasikan pada aplikasi MATLAB menggunakan SIMULINK toolbox. Simulasi gimbal 2-sumbu yang digunakan pada penelitian ini ditunjukkan pada Gambar 6. 


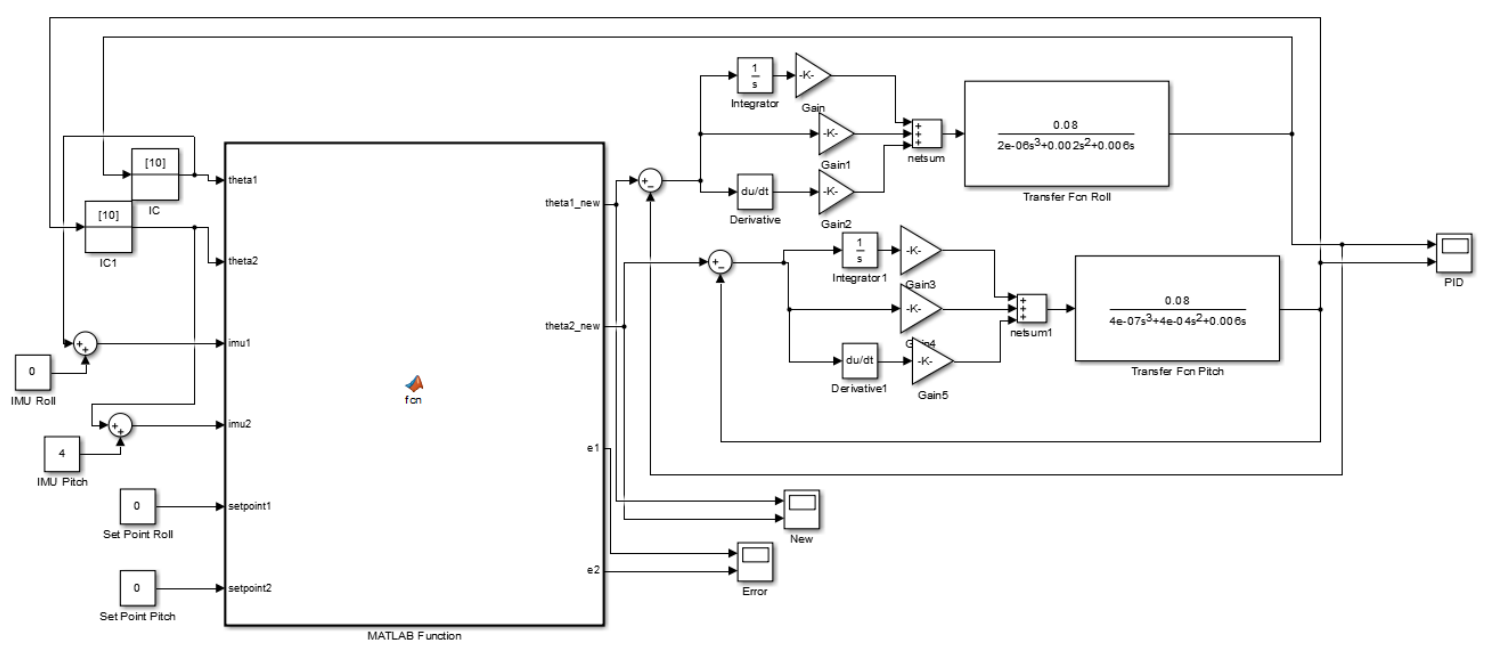

Gambar 6 Simulasi gimbal 2-sumbu

\subsection{Hasil Pengujian Kendali PID}

Dari simulasi dan validasi hasil pengujian didapatkan nilai dari konstanta $\mathrm{Kp}, \mathrm{Ki}$, dan $\mathrm{Kd}$ untuk sumbu pitch dan roll. Untuk sumbu pitch didapatkan nilai dari konstanta $\mathrm{Kp}$, Ki, dan Kd masing-masing yaitu 43,2; 15,7; dan 0,1. Sedangkan untuk sumbu roll didapatkan nilai dari konstanta $\mathrm{Kp}, \mathrm{Ki}$, dan $\mathrm{Kd}$ masing-masing yaitu 11,4; 22,3; dan 0,12. Grafik dari pengujian ini dapat dilihat pada Gambar 7.

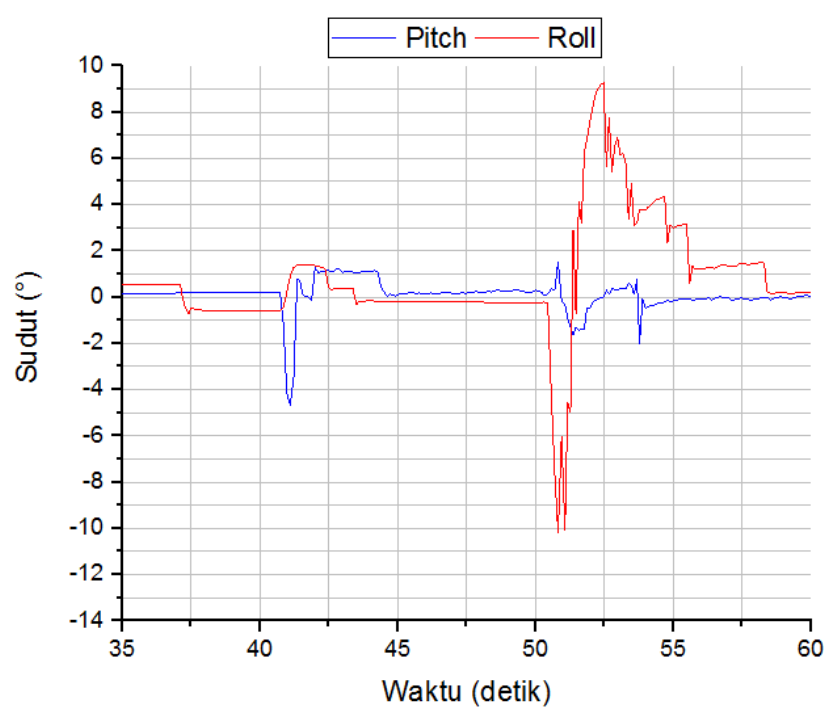

Gambar 7 Grafik hasil kendali PID pada gimbal 2-sumbu

Pada Gambar 7, untuk grafik sumbu pitch pada saat terjadi ganggauan sebesar $-4,67^{\circ}$ respon sistem mengalami risetime sebesar 0,12 detik. Overshoot yang terjadi yaitu sebesar $1,37^{\circ}$. Steady state error yang terjadi yaitu sebesar $0,42^{\circ}$ dan settlingtime sebesar 0,25 detik.

Sedangkan untuk sumbu roll terlihat pada saat terjadi gangguan sebesar $-10,07^{\circ}$ respon sistem mengalami risetime sebesar 1,31 detik. Overshoot yang terjadi yaitu sebesar 9,28 . Steady state error yang terjadi yaitu sebesar $0,01^{\circ}$ dan settlingtime sebesar 4,52 detik.

\subsection{Hasil Pengujian Kendali PID Fuzzy}

Dari percobaan sebelumnya telah didapatkan nilai untuk nilai konstanta PID untuk pitch dan roll. Nilai konstanta PID tersebut akan menjadi nilai $\mathrm{O}$ pada rentang nilai himpunan. 
Kemudian berdasarkan nilai $\mathrm{O}$ tersebut dilakukan eksperimen untuk $\mathrm{Kp}$ dan $\mathrm{Ki}$ dengan nilai $\mathrm{A}$ yaitu nilai maksimum, sedangkan Kd dengan nilai B yaitu nilai yang minimum. Setelah itu dilakukan eksperimen untuk Kp dan Ki dengan nilai B yaitu nilai yang minimum, sedangkan Kd dengan nilai A yaitu nilai maksimum. Pergeseran nilai Kp, KI, dan Kd dilakukan sedemikian rupa agar interval pergeseran pada nilai maksimum dan minimum dari rentang himpunan bernilai seperti pada Gambar 4. Pengambilan nilai maksimum dan minimun tersebut juga dilihat dari respon yang dihasilkan masih memenuhi spesifikasi sistem yang diinginkan.

Untuk sumbu pitch, didapatkan nilai keluaran fuzzy berupa nilai $\mathrm{Kp}$ dengan rentang nilai 40,2 hingga 46,2, nilai Ki dengan rentang nilai 10,7 hingga 20,7, dan nilai $\mathrm{Kd}$ dengan rentang nilai 0,05 hingga 0,15 . Untuk sumbu roll, didapatkan nilai keluaran fuzzy berupa nilai Kp dengan rentang nilai 6,4 hingga 16,4, nilai Ki dengan rentang nilai 17,3 hingga 27,3, dan nilai Kd dengan rentang nilai 0,08 hingga 0,16.

Untuk masukan fuzzy pada sumbu pitch dan roll berupa nilai error dengan rentang nilai $-30^{\circ}$ hingga $30^{\circ}$, dan nilai delta error dengan rentang nilai $-10^{\circ}$ hingga $10^{\circ}$. Nilai rentang masukan fuzzy diambil dari pengujian dan batasan dari kinematika gimbal yang digunakan. hasil Grafik dari pengujian ini dapat dilihat pada Gambar 8.

Pada Gambar 8 untuk grafik sumbu pitch pada saat terjadi ganggauan sebesar $-3,90^{\circ}$ respon sistem mengalami risetime sebesar 0,12 detik. Overshoot yang terjadi yaitu sebesar $1,01^{\circ}$. Steady state error yang terjadi yaitu sebesar $0,10^{\circ}$ dan settlingtime sebesar 0,47 detik.

Sedangkan untuk sumbu roll terlihat pada saat terjdai gangguan sebesar $-7,97^{\circ}$ respon sistem mengalami risetime sebesar 1,07 detik. Overshoot yang terjadi yaitu sebesar $7,80^{\circ}$. Steady state error yang terjadi yaitu sebesar $0,23^{\circ}$ dan settlingtime sebesar 2,10 detik.

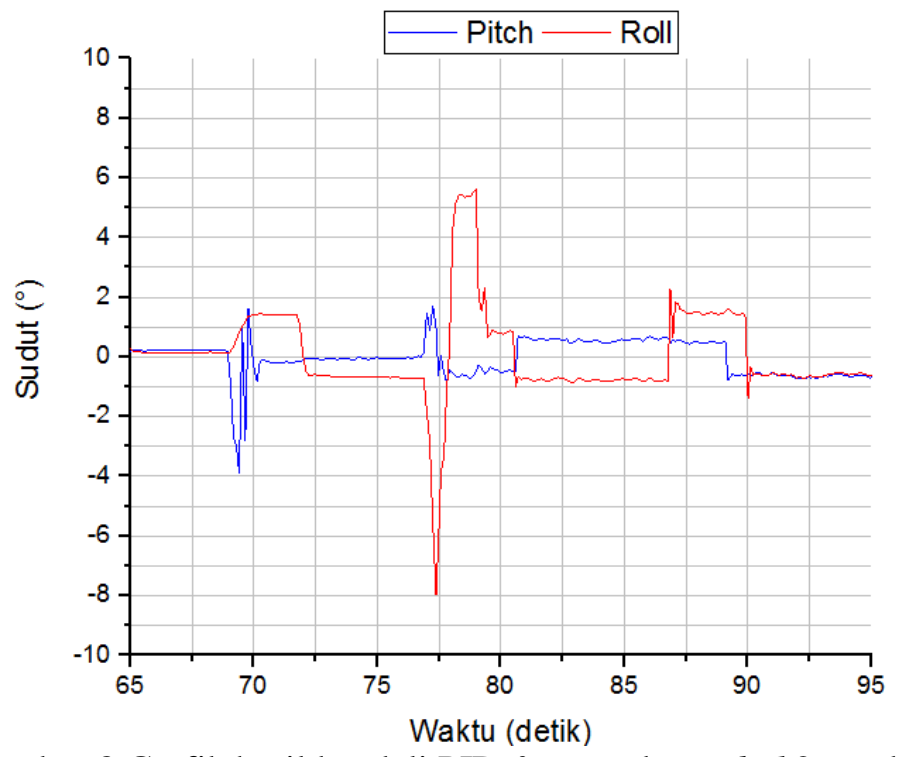

Gambar 8 Grafik hasil kendali PID fuzzy pada gimbal 2-sumbu

\subsection{Hasil Pengujian Kendali PID Fuzzy}

Setelah telah dilakukan pengujian pada sumbu pitch dan roll pada gimbal dengan kedali PID dan PID fuzzy, dibuat tabel untuk memudahkan pembandingan antara kedua metode tersebut yang disajikan pada Tabel 2 .

Untuk risetime yang baik pada kendali PID dan PID fuzzy dihasilkan nilai yang hampir sama pada sumbu pitch maupun roll. sedangkan untuk overshoot dihasilkan nilai yang lebih baik pada kendali PID fuzzy pada sumbu pitch maupun roll. kemudian untuk nilai steday state error dihasilkan nilai yang lebih baik pada sumbu pitch menggunakan kendali PID fuzzy sedangkan pada sumbu roll menggunkan kendali PID. Untuk nilai settlingtime dihasilkan nilai 
yang lebih baik pada sumbu pitch menggunakan kendali PID sedangkan sumbu roll menggunakan kendali PID fuzzy.

Tabel 2 Perbandingan hasil kendali PID dan PID fuzzy pada gimbal 2-sumbu

\begin{tabular}{|l|r|r|r|r|}
\hline \multirow{2}{*}{ Error $\left({ }^{\circ}\right)$} & \multicolumn{2}{|c|}{ Pitch } & \multicolumn{2}{c|}{ Roll } \\
\cline { 2 - 5 } & \multicolumn{1}{|c|}{ PID } & PID fuzzy & \multicolumn{1}{c|}{ PID } & \multicolumn{1}{c|}{ PID fuzzy } \\
\cline { 2 - 5 } & $\mathbf{- 4 , 6 7}$ & $\mathbf{- 3 , 9 0}$ & $\mathbf{- 1 0 , 0 7}$ & $\mathbf{- 7 , 9 7}$ \\
\hline Risetime(detik) & 0,12 & 0,12 & 1,31 & 1,07 \\
\hline Overshoot $^{\circ}$ ) & 1,37 & 1,01 & 9,28 & 7,80 \\
\hline Steadystate $\left({ }^{\circ}\right)$ & 0,42 & 0,10 & 0,01 & 0,23 \\
\hline Settlingtime(detik) & 0,25 & 0,47 & 4,52 & 2,10 \\
\hline
\end{tabular}

Untuk sumbu pitch, nilai ristetime dan overshoot yang dihasilkan pada kendali PID dan kendali PID fuzzy memiliki nilai yang hampir sama. sedangkan steady state error dihasilkan nilai yang lebih baik menggunakan kendali PID fuzzy. Kemudian untuk nilai settlingtime dihasilkan nilai yang lebih baik menggunakan kendali PID.

Untuk sumbu roll, nilai ristetime yang dihasilkan pada kendali PID dan kendali PID fuzzy memiliki nilai yang hampir sama. sedangkan steady state error dihasilkan nilai yang lebih baik menggunakan kendali PID. Kemudian untuk nilai overshoot dan settlingtime dihasilkan nilai yang lebih baik menggunakan kendali PID fuzzy.

Sudut yang dihasilkan pada sumbu roll antara kendali PID dan kendali PID fuzzy memiliki perbedaan nilai yang besar yaitu $2,90^{\circ}$. Hal tersebut terjadi karena mekanik dari gimbal yang digunakan mempengaruhi respon sistem. Dapat dilihat pada Gambar 7 dan Gambar 8 saat sumbu roll (body 1) mendapat gangguan maka sumbu pitch (body 2) atau end effector juga akan mengalami sedikit gangguan sehingga akan mempengaruhi respon dari sumbu roll (body 1). Pada Gambar 7 dan Gambar 8 dapat dilihat pada saat roll mendapat gangguan, kendali PID fuzzy dapat menangani ganguan lebih baik pada sumbu pitch yang akan mempengaruhi respon sumbu roll dibandingkan kendali PID.

\section{KESIMPULAN}

Berdasarkan hasil pengamatan, pengujuan dan analisis pada hasil yang diperoleh dari penelitian dapat disimpulkan, telah berhasil dirancang dan dibuat sistem kendali gimbal 2sumbu yang dapat menjaga orientasi posisi kamera menggunakan metode PID fuzzy dengan nilai keluaran fuzzy berupa nilai Kp dengan rentang nilai 40,2 hingga 46,2, nilai Ki dengan rentang nilai 10,7 hingga 20,7, dan nilai Kd dengan rentang nilai 0,05 hingga 0,15 pada sumbu pitch. sedangkan keluaran fuzzy berupa nilai Kp dengan rentang nilai 6,4 hingga 16,4, nilai Ki dengan rentang nilai 17,3 hingga 27,3, dan nilai Kd dengan rentang nilai 0,08 hingga 0,16 pada sumbu roll. Untuk masukan fuzzy pada sumbu pitch dan roll berupa nilai error dengan rentang nilai $-30^{\circ}$ hingga $30^{\circ}$, dan nilai delta error dengan rentang nilai $-10^{\circ}$ hingga $10^{\circ}$.

Untuk risetime, dihasilkan nilai yang sama antara kendali PID dan kendali PID fuzzy baik pada sumbu pitch maupun roll. Untuk overshoot, pada sumbu pitch nilai ditunjukkan oleh kendali PID dan PID fuzzy bernilai sama, dan pada sumbu roll nilai yang lebih baik ditunjukkan oleh kendali PID fuzzy. Untuk steady state error, pada sumbu pitch nilai yang lebih baik ditunjukkan oleh kendali PID fuzzy, sedangkan pada sumbu roll nilai yang lebih baik ditunjukkan oleh kendali PID. Untuk settlingtime, pada sumbu pitch nilai yang lebih baik ditunjukkan oleh kendali PID, sedangkan pada sumbu roll nilai yang lebih baik ditunjukkan oleh kendali PID fuzzy. 


\section{SARAN}

Pada penelitian ini masih terdapat beberapa hal yang perlu disempurnakan. Perlu adanya sistem kendali yang mampu menentukan kecepatan gerak gimbal secara adaptif berbanding lurus terhadapat perubahan error yang terjadi, sehingga gimbal akan dapat merespon lebih baik ketika terjadi perubahan orientasi. Selain itu perlu ditambahkan program untuk kalkulasi kecepatan dalam satu kali program berjalan, sehingga dapat memaksimalkan respon gimbal.

\section{DAFTAR PUSTAKA}

[1] Rajesh, R.J. and Kavitha, P., 2015, Camera gimbal stabilization using conventional PID controller and evolutionary algorithms, 2015 International Conference on Computer, Communication and Control (IC4), September 2015 IEEE., pp. 1-6.

[2] Ogata, K., 2010, Modern Control Engineering, Prentice Hall, New Jersey.

[3] Passino, K.M. and Yurkovich, S., 1998, Fuzzy Control, Addison Wesley Longman, Inc., California.

[4] Perwira, Z. Y., 2016, Implementasi Metode PID (Proportional Integral Derivative) Fuzzy pada Sistem Penerbangan Quadrotor untuk Penelusuran Lorong Berbelok, Tesis, Program Sarjana Elektronika dan Instrumentasi, Univ. Gadjah Mada, Yogyakarta.

[5] Abbasi, E. and Mahjoob, M., 2013, Controlling of Quadrotor UAV Using a Fuzzy System for Tuning the PID Gains in Hovering Mode, Tesis, School of Mechanical Engineering, University of Tehran.

[6] A. Dharmawan and R. Handoyo, "Sistem Stabilisasi Posisi Kamera pada Quadcopter," IJEIS (Indonesian J. Electron. Instrum. Syst., vol. 2, no. 2, pp. 109-118, 2012 [Online]. Available: https://jurnal.ugm.ac.id/ijeis/article/view/2421. [Accessed: 21-Apr-2017]

[7] Rajesh, R.J. and Ananda, C.M., 2015, PSO tuned PID controller for controlling camera position in UAV using 2-axis gimbal, 2015 International Conference on Power and Advanced Control Engineering (ICPACE), August 2015 IEEE., pp. 128-133,

[8] Jazar, R.N., 2007, Theory of Applied Robotics, Springer US, New York.

[9] Kleuver, C.A., 2015, Dynamic System: Modeling, Simulation, and Control, Wiley.

[10] Hibbeler, R.C., 2016, Dynamics, Prentice Hall, New Jersey.

[11] Santos, M., López, V. and Morata, F., 2010, Intelligent fuzzy controller of a quadrotor, Proceedings of 2010 IEEE International Conference on Intelligent Systems and Knowledge Engineering, ISKE 2010, 141-146.

[12] Abdo, M., 2014, Modeling control and simulation of two axes gimbal seeker using fuzzy PID controller, The 22nd Iranian Conference on Electrical Engineering, (Icee), $1342-1347$, 